\title{
Experimental Study of Diesel Engine Power Test Based on the No-Load Power Measuring
}

\author{
Xiaohua Xiao ${ }^{1}$, Yuheng $\mathrm{Li}^{2}$, Jiajia $\mathrm{Jing}^{3}$, Wenquan Wang ${ }^{4}$ \\ ${ }^{1,2}$ School of Mechanical Engineering, Southwest Petroleum University, Chengdu, 610500, China
}

3, 4Safety and Environmental Protection of Quality Supervision, CNPC Chuanqing Drilling Engineering Co. , Ltd. , Guanghan Sichuan, 618300, China

\begin{abstract}
In view of the fact that the traditional dynamometer can not test diesel engine power in the production site, based on the principle of No-Load Power Measuring, a mathematical model between the maximum power of diesel engine and crankshaft speed, equivalent moment of inertia and acceleration time was established. And a set of diesel power test system was set up in which the NET2801 data acquisition card is the core. The time-speed curve of the diesel engine acceleration and deceleration process is obtained by MATLAB software programming. The equivalent moment of inertia and the maximum power of the diesel engine are deduced. The reliability of the test method is verified and the cause of the error is analyzed, which provides a research idea to improve the field test accuracy of diesel engine power.
\end{abstract}

Keywords: diesel engine power; No-Load Power Measuring; equivalent moment of inertia; Instantaneous speed

\section{Introduction}

As an important power equipment for drilling wells, the maximum power value of the diesel engine will decrease with the increase of the use time ${ }^{[1]}$. The best way to master the overall technical condition of a diesel engine is to measure its existing maximum power ${ }^{[2]}$. The traditional power test instrument ${ }^{[3]}$ is generally a dedicated test bench that is fixed in the room. It need to carry the diesel engine from the production site after the demolition back to the test center when testing, which is time consuming and costly. The No-Load Power Measuring ${ }^{[4]}$ is a convenient and quick power test method, which do not need a dedicated test bench and can be applied to diesel engine in the production site. The research of No-Load Power Measuring rose in the automotive industry ${ }^{[5]}$. When the engine is idling, the throttle is suddenly added to the maximum position. At the same time, the instrument is used to continuously acquire the amount of change in crankshaft speed and the effective power is expressed by the acceleration power. According to the principle of No-Load Power Measuring in this paper, the maximum power calculation model was established, and the corresponding power test system was developed. The power test system was used to test the maximum power of the diesel engine in production site, and the power test results were analyzed, which provides a research direction for further improving the stability and calculation accuracy of power test.

\section{Principle of No-Load Power Measuring of diesel engine}

2.1 Test principle of equivalent moment of inertia of diesel engine

The equivalent moment of inertia is a necessary parameter for No-Load Power Measuring ${ }^{[6]}$, which represents the sum of the moment of inertia of all rotary motion parts centered on the crankshaft. At present, there are several main measurement methods, namely, Calculation Method ${ }^{[7]}$, Instantaneous Speed Method ${ }^{[8]}$, No-Load Deceleration Method $^{[9]}$ and Additional Mass Method ${ }^{[10]}$. It is necessary to know the parts size and material of diesel engine when using the Calculation Method, and the calculation process is cumbersome and difficult. When using the Instantaneous Speed Method and No-Load Deceleration Method, the diesel cylinder pressure needs to be measured, but there is no way to install a pressure sensor because there is generally no pressure test hole on the diesel engines in production site.

In this paper, the practical Additional Mass Method is used to test the equivalent moment of inertia of diesel engine. Its principle is as follows.

$$
J=\frac{J^{\prime} \cdot \frac{d n^{\prime}}{d t}}{\frac{d n}{d t}-\frac{d n^{\prime}}{d t}}
$$

Where, $J$ is the equivalent moment of inertia of diesel engine, $\mathrm{kg} \cdot \mathrm{m}^{2} \cdot \frac{d n}{d t}$ is the speed acceleration of diesel engine, r/min . s. $J^{\prime}$ is the moment of inertia of the additional mass, $\mathrm{kg} \cdot \mathrm{m}^{2} . \frac{d n^{\prime}}{d t}$ is the speed acceleration of diesel engine with the additional mass, $\mathrm{r} / \mathrm{min} \cdot \mathrm{s}$.

According to the Equation (1), the equivalent moment of inertia of the diesel engine can be obtained by measuring the 


\section{International Journal of Science and Research (IJSR) \\ ISSN (Online): 2319-7064}

Index Copernicus Value (2015): 78.96 | Impact Factor (2015): 6.391

speed acceleration of the diesel engine during the free deceleration process and the speed acceleration of the diesel engine with the additional mass.

\subsection{Power test principle}

There are two power calculation models in the principle of No-Load Power Measuring, one of which is to calculate the instantaneous power, the other is to calculate the average power. The instantaneous power calculation model is shown in Equation (2).

$$
P_{e}=K_{1} \cdot \frac{\pi J}{9550 \times 30} \cdot n \cdot \frac{d n}{d t}
$$

Where, $P_{e}$ is the instantaneous power at the speed $n$ of the diesel engine during acceleration, $\mathrm{kW} . \quad n$ is the instantaneous speed of diesel engine, r/min. $K_{1}$ is the

\section{Power correction factor.}

According to the Equation (2), in order to obtain the maximum effective power, it is necessary to know the acceleration at the rated speed during the crankshaft acceleration process. However, when diesel engine is accelerated to near the maximum speed, the acceleration at the rated speed is difficult to obtain as the speed acceleration value has been reduced. Therefore, this calculation model is not used in this paper.

The average power calculation model is shown in Equation (3).

$$
P_{\max }=K_{2} \cdot \frac{J \pi^{2}\left(n_{2}^{2}-n_{1}^{2}\right)}{1800000 \Delta T}
$$

Where, $P_{\max }$ is the maximum power of diesel engine after the correction, $\mathrm{kW} . n_{1}$ is the starting speed in the measuring range, r/min. $n_{2}$ is the ending speed in the measuring range, $\mathrm{r} / \mathrm{min} . \Delta T$ is the acceleration time from speed $n_{1}$ to speed $n_{2}$, s. $K_{2}$ is the Power correction factor.

Under the condition of already knowing the equivalent moment of inertia $J$, we can calculate the average power of the diesel engine as long as we know starting speed $n_{1}$ and ending speed $n_{2}$ and its corresponding time increments $\Delta T$. And the maximum power is the value of the average power calibrated by the power correction factor
$K_{2}$. Therefore, the average power calculation model is the theoretical basis of this paper.

\section{Design of the power test system}

According to the principle of No-Load Power Measuring, the acceleration and deceleration test only need to be carried out after installing an additional mass with known moment of inertia, the diesel engine power can be measured. And the acceleration and deceleration test is to test the instantaneous speed signal during the acceleration and deceleration process $^{[11]}$.

The design of the additional mass is to be followed by principles such as ease of manufacture, ease of calculation, small air friction and better balance. According to this, the ring-shaped additional mass as shown in Figure 1 was designed in this paper, which is installed in the diesel flywheel end.

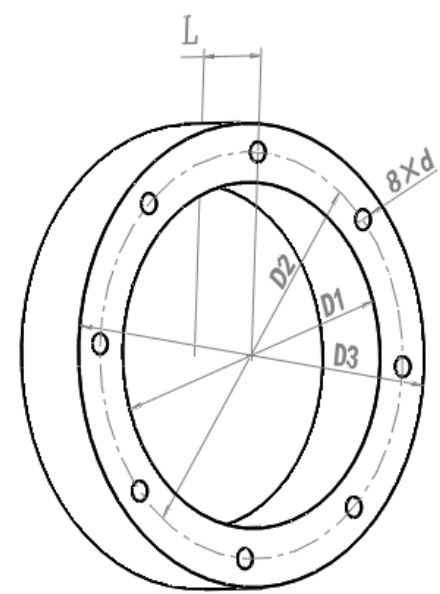

Figure 1: Shape of the additional mass

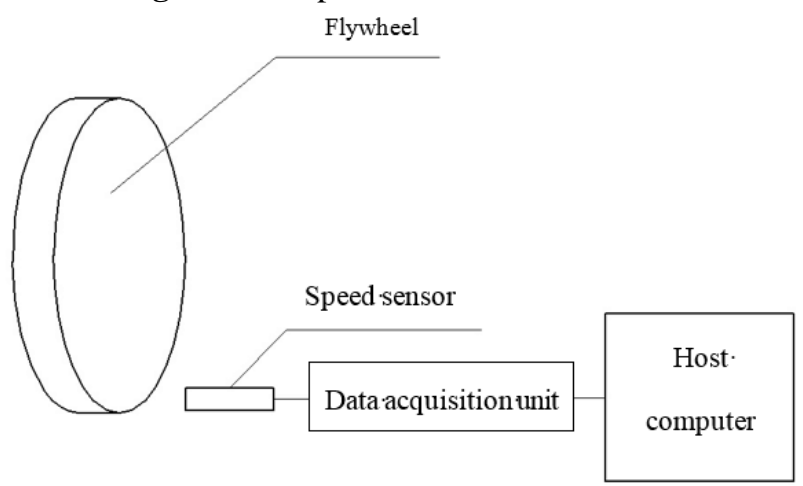

Figure 2: Block diagram of the power test system

The moment of inertia of the additional mass is calculated by the following formula ${ }^{[12]}$.

$$
J_{0}=\frac{\pi \rho L}{32}\left(D_{3}^{4}-D_{1}^{4}\right)-\frac{\pi \rho L}{2} \cdot D_{2}^{2} \cdot d^{2}
$$

Where, $\rho$ is the density of the additional mass material.

As shown in Figure 2, the entire data acquisition system is mainly composed of speed sensor, data acquisition instrument and host computer ${ }^{[13]}$. The speed sensor is a magnetoelectric sensor whose model is LM18-3008PA. The 


\section{International Journal of Science and Research (IJSR) \\ ISSN (Online): 2319-7064 \\ Index Copernicus Value (2015): 78.96 | Impact Factor (2015): 6.391}

data acquisition instrument is NET2801 data acquisition system. The magnetoelectric speed sensor is installed in the diesel engine test hole, and its distance from the flywheel tooth tip is kept at $2 \sim 4 \mathrm{~mm}$. When diesel engine is running, the sensor output signal is periodically changed. The output signal is filtered and shaped by signal conditioning board to obtain the pulse signal as shown in Figure 3. Each pulse signal corresponds to the teeth of the flywheel. The time between each two pulse signals is calculated from the clock frequency and count value between the two pulses, so that the instantaneous speed of the crankshaft is obtained ${ }^{[14]}$.

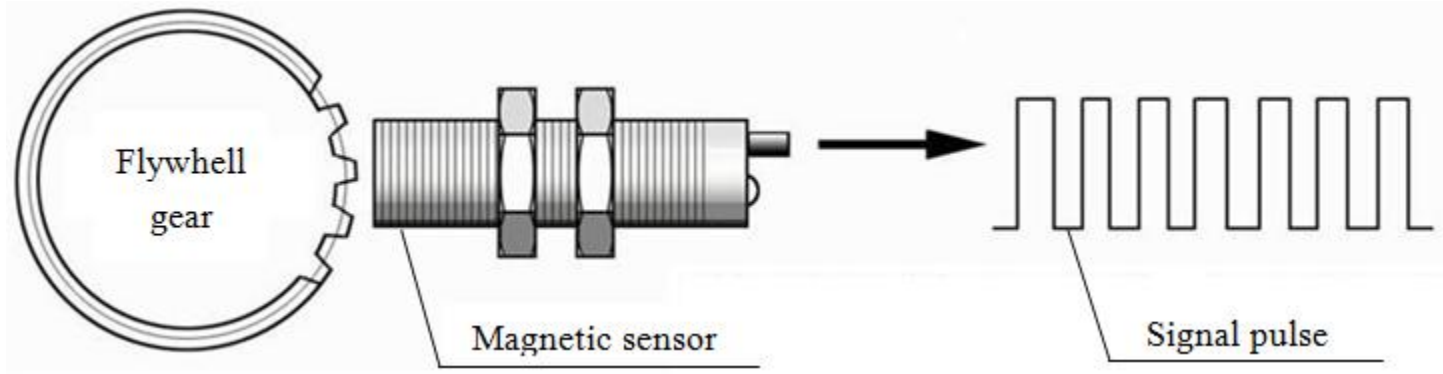

Figure 3: Measurement principle of magnetoelectric sensor

\section{Analysis of test results}

Three different types of diesel engines in the drilling site were selected to perform the maximum power test. The test process is divided into two parts: test of equivalent moment of inertia and power test. The specific parameters of three diesel engines are shown in Table 1. After the test experiment is completed, the digital pulse signal is converted to the diesel engine speed curve for subsequent processing by MATLAB software.

Table 1: Technical parameters of diesel engines

\begin{tabular}{|c|c|c|c|c|}
\hline Model number & $\begin{array}{c}\text { Rated } \\
\text { power(kW) }\end{array}$ & $\begin{array}{c}\text { Rated } \\
\text { speed(r/min) }\end{array}$ & $\begin{array}{c}\text { Number of } \\
\text { cylinders }\end{array}$ & $\begin{array}{c}\text { Years of } \\
\text { service }\end{array}$ \\
\hline BG12V190PZLG-3 & 810 & 1300 & 12 & 1 \\
\hline CAT 3406 & 269 & 1800 & 6 & 4 \\
\hline CAT 3408 & 354 & 2100 & 6 & 12 \\
\hline
\end{tabular}

3.1 Analysis of test results of equivalent moment of inertia

When calculating the speed acceleration value, a speed curve with good linearity was selected in MATLAB software firstly. And then, as shown in Figure 4 and Figure 5 , the acceleration value can be obtained by simple calculation $\frac{\Delta n}{\Delta T}$ according to the speed difference $\Delta n$ between starting speed and ending speed and corresponding time interval $\Delta T$.

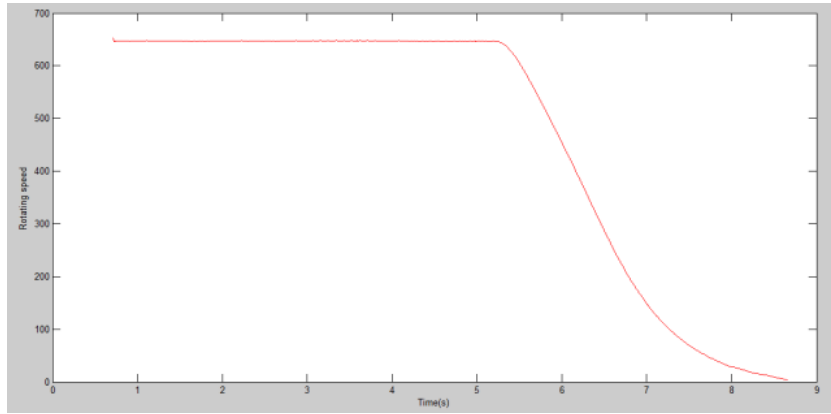

Figure 4: Non-load deceleration curve of diesel engine

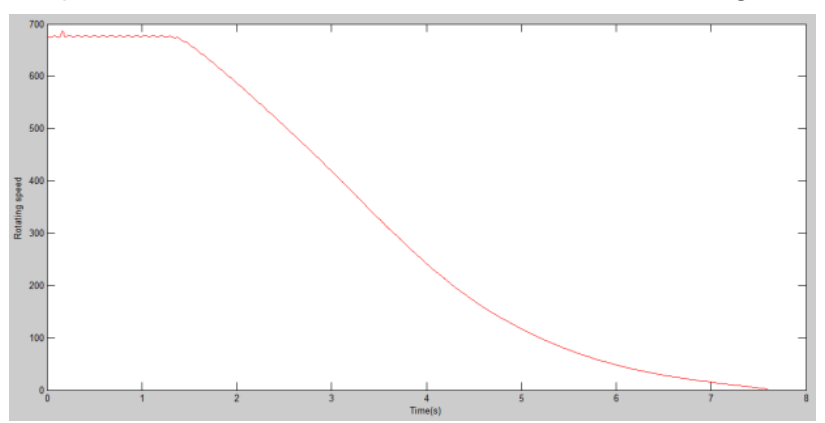

Figure 5: Deceleration curve after installing the additional mass on diesel engine

The speed curves with good linearity from 530r/min to $580 \mathrm{r} / \mathrm{min}$ were selected to calculate the acceleration value for three kinds of diesel engines in Table 1. The calculation results of acceleration value and equivalent moment of inertia are shown in Table 2.

Table 2: Test results of equivalent moment of inertia of diesel engine

\begin{tabular}{|c|c|c|c|c|c|c|}
\hline $\begin{array}{l}\text { Model } \\
\text { number }\end{array}$ & $\begin{array}{c}\text { Number of } \\
\text { test times }\end{array}$ & $\begin{array}{c}\text { No-load deceleration } \\
\text { value }(\mathrm{r} / \mathrm{min} \cdot \mathrm{s})\end{array}$ & $\begin{array}{c}\text { Deceleration value with } \\
\text { additional mass }(r / m i n ~ \cdot s)\end{array}$ & $\begin{array}{c}\text { Equivalent moment of } \\
\text { inertia }\left(\mathrm{kg} \cdot \mathrm{m}^{2}\right)\end{array}$ & $\begin{array}{c}\text { Average value } \\
\left(\mathrm{kg} \cdot \mathrm{m}^{2}\right)\end{array}$ & $\begin{array}{c}\text { Coefficient of } \\
\text { Variation } \\
\end{array}$ \\
\hline \multirow{4}{*}{$\begin{array}{l}\text { BG12V190 } \\
\text { PZLG-3 }\end{array}$} & 1 & -182.235 & -152.863 & 31.220 & \multirow{4}{*}{30.321} & \multirow{4}{*}{$1.74 \%$} \\
\hline & 2 & -180.870 & -150.612 & 29.866 & & \\
\hline & 3 & -181.121 & -151.053 & 30.142 & & \\
\hline & 4 & -180.981 & -150.865 & 30.057 & & \\
\hline \multirow{2}{*}{ CAT 3406} & 1 & -218.554 & -184.270 & 10.750 & \multirow{2}{*}{12.268} & \multirow{2}{*}{$9.02 \%$} \\
\hline & 2 & -220.036 & -188.430 & 11.924 & & \\
\hline
\end{tabular}


International Journal of Science and Research (IJSR)

ISSN (Online): 2319-7064

Index Copernicus Value (2015): 78.96 | Impact Factor (2015): 6.391

\begin{tabular}{|c|c|c|c|c|c|c|}
\hline & 3 & -223.877 & -195.552 & 13.808 & & \\
\hline & 4 & -222.639 & -192.120 & 12.590 & & \\
\hline \multirow{4}{*}{ CAT 3408} & 1 & -221.136 & -196.650 & 16.062 & \multirow{4}{*}{18.221} & \multirow{4}{*}{$30.47 \%$} \\
\hline & 2 & -203.334 & -188.881 & 26.137 & & \\
\hline & 3 & -209.241 & -190.025 & 19.778 & & \\
\hline & 4 & -215.403 & -182.023 & 10.906 & & \\
\hline
\end{tabular}

According to the calculation results in Table 2, it can be seen that the acceleration values of BG12V190PZLG-3 diesel engine in four tests are less discrete during the same speed range, and the calculated equivalent moments of inertia of diesel engine are relatively stable. The coefficient of variation is only $1.74 \%$ and test results are good. The acceleration values of CAT3406 diesel engine in four tests fluctuate slightly during the same speed range, and the calculated equivalent moments of inertia of the diesel engine are between $10.750 \mathrm{~kg} \cdot \mathrm{m}^{2}$ and $13.808 \mathrm{~kg} \cdot \mathrm{m}^{2}$. However, the minimum calculated result of equivalent moment of inertia of CAT3408 diesel engine is $10.906 \mathrm{~kg}$. $\mathrm{m}^{2}$ and the maximum value is $26.137 \mathrm{~kg} \cdot \mathrm{m}^{2}$, which indicates that the discretization of results is very serious. By comparing the speed curves of four tests, it can be seen that the curve coincidence degree is low and the randomness is large. Therefore, the equivalent moment of inertia of this diesel engine can not be determined accurately.

After analysis, the factors that affect the test accuracy of equivalent moment of inertia are as follows.

(1) Years of service

When testing, the BG12V190PZLG-3 diesel engine was only used for one year, and the technical condition was good. There is a high degree of coincidence for speed curves during many tests. And thus the calculated moment of inertia is stable and reliable. However, CAT3408 diesel engine has been serving for 12 years in the drilling site, which means a long period of continuous work and many different levels of maintenance. Due to a variety of factors such as mechanical wear and poor lubrication, the stability of speed curve is poor. The calculated speed acceleration value fluctuates greatly and a uniform moment of inertia value can not be obtained under this test method.

(2)System error of time interval $\Delta T$

In the actual measurement, the speed $n$ is the average speed after a certain angle, rather than the instantaneous speed of a moment. There may not be exactly the speed of $530 \mathrm{r} / \mathrm{min}$ and $580 \mathrm{r} / \mathrm{min}$ during the sampling process, then starting time and ending time of the time interval $\Delta T$ will appear random error, which has an impact on the calculation of speed acceleration.

(3)Test error caused by operation

When diesel engine is running, there is a large vibration on engine body. If the speed sensor can not be installed firmly, it can not collect a complete and accurate signal, which will have a direct impact on the measurement of speed. If the warm-up time of diesel engine is insufficient before the test, the lubricant temperature does not reach normal operating temperature and the deceleration process speed curve can not be measured accurately. In order to eliminate the error caused by the test operation, we can solve it by repeated measurements.

\subsection{Analysis of diesel power test results}

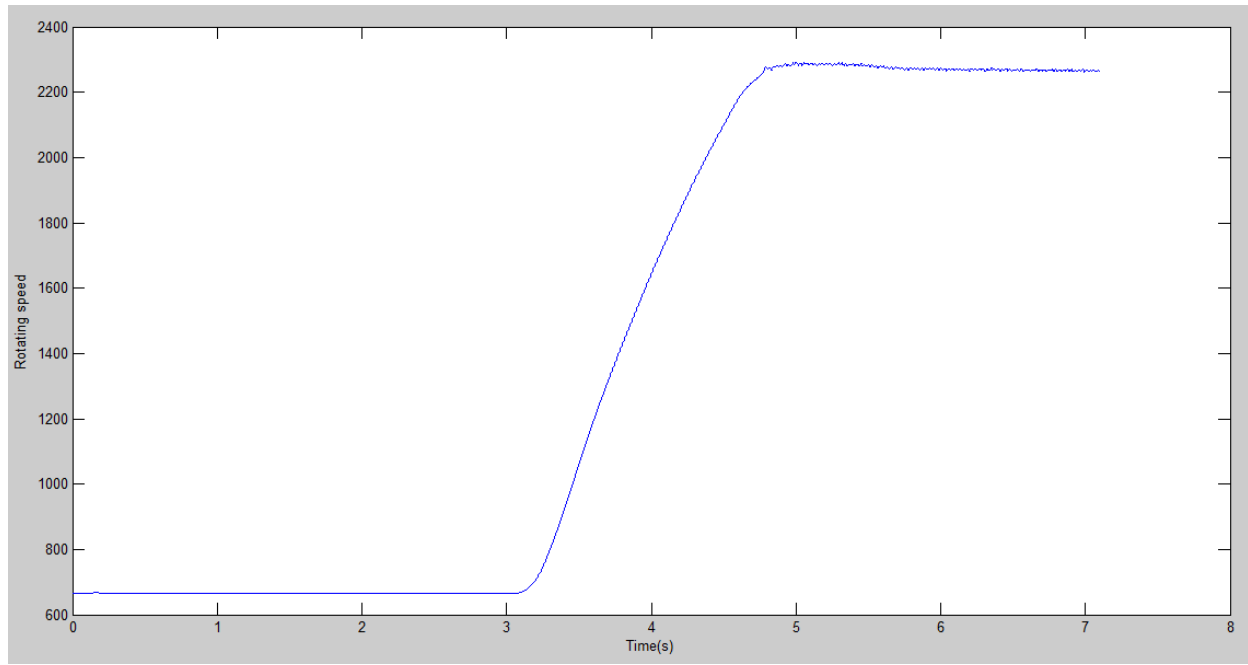

Figure 6: No-load acceleration curve of diesel engine

The no-load acceleration curve of diesel engine is shown in Figure 6. A speed curve with good linearity was selected to calculate the average power and the maximum power can be obtained by calibrating the average power. According to the Equation (3), it is important to measure the stability of the

Volume 6 Issue 7, July 2017 www.ijsr.net

Licensed Under Creative Commons Attribution CC BY 


\section{International Journal of Science and Research (IJSR)}

ISSN (Online): 2319-7064

Index Copernicus Value (2015): 78.96 | Impact Factor (2015): 6.391

calculation results $\frac{n_{2}^{2}-n_{1}^{2}}{\Delta T}$ in the acceleration process.

The test data processing results are shown in Table 3 after

Table 3: Data processing results of no-load acceleration

\begin{tabular}{|c|c|c|c|c|c|}
\hline $\begin{array}{l}\text { Model } \\
\text { number }\end{array}$ & $\begin{array}{c}\text { Serial } \\
\text { number }\end{array}$ & $\begin{array}{c}\text { Starting and } \\
\text { ending time(s) }\end{array}$ & $\begin{array}{l}\text { Starting and ending } \\
\text { speed }(\mathrm{r} / \mathrm{min})\end{array}$ & $\frac{n_{2}^{2}-n_{1}^{2}}{\Delta T}\left(\mathrm{r}^{2} / \mathrm{s}^{3}\right)$ & Average power $(\mathrm{kW})$ \\
\hline \multirow{6}{*}{$\begin{array}{l}\text { BG12V190 } \\
\text { PZLG-3 }\end{array}$} & \multirow{2}{*}{1} & 0.542 & 807.749 & \multirow{2}{*}{424.793} & \multirow{6}{*}{689.775} \\
\hline & & 1.212 & 1295.013 & & \\
\hline & \multirow{2}{*}{2} & 0.281 & 811.605 & \multirow{2}{*}{424.736} & \\
\hline & & 0.953 & 1298.547 & & \\
\hline & \multirow{2}{*}{3} & 0.328 & 818.567 & \multirow{2}{*}{426.371} & \\
\hline & & 0.998 & 1303.249 & & \\
\hline \multirow{6}{*}{ CAT 3406} & \multirow{2}{*}{1} & 6.017 & 1063.022 & \multirow{2}{*}{897.041} & \multirow{6}{*}{211.146} \\
\hline & & 6.848 & 1952.580 & & \\
\hline & \multirow{2}{*}{2} & 6.064 & 1138.211 & \multirow{2}{*}{888.691} & \\
\hline & & 6.658 & 1787.995 & & \\
\hline & \multirow{2}{*}{3} & 6.027 & 1082.753 & \multirow{2}{*}{897.676} & \\
\hline & & 6.661 & 1794.872 & & \\
\hline \multirow{6}{*}{ CAT 3408} & \multirow{2}{*}{1} & 0.927 & 964.187 & \multirow{2}{*}{636.734} & \multirow{6}{*}{203.026} \\
\hline & & 1.769 & 1690.821 & & \\
\hline & \multirow{2}{*}{2} & 0.945 & 984.529 & \multirow{2}{*}{649.780} & \\
\hline & & 1.762 & 1696.970 & & \\
\hline & \multirow{2}{*}{3} & 0.869 & 913.242 & \multirow{2}{*}{618.699} & \\
\hline & & 1.550 & 1515.152 & & \\
\hline
\end{tabular}

It can be seen from the calculation results of $\frac{n_{2}^{2}-n_{1}^{2}}{\Delta T}$ in

Table 3 that the average power calculation has a small range of fluctuations, and there is still a systematic error effect of the time interval $\Delta T$.

But the degree of dispersion of calculation results is small. It is feasible to test the maximum power of diesel engine at production site, which indicates that the average power calculation model is feasible both in theory and practice.

\section{Conclusion}

According to the principle of No-Load Power Measuring, a practical power test system has been developed for the diesel engine at production site. It has been proved through many field tests that the No-Load Power Measuring technology can achieve the measurement of the maximum power in the case of non-demolition for diesel engine, but there is also a need for further optimization. In order to improve the accuracy and stability of diesel engine power test, the following two optimization must be carried out on the basis of the existing technology.

(1) It is necessary to find a way to easily and accurately determine the equivalent moment of inertia of old diesel engine.

(2) It is necessary to perform appropriate data smoothing and data fitting on the instantaneous speed signal to substituting the corresponding moment of inertia in Table 2. eliminate the systematic error of the time interval $\Delta T$.

\section{References}

[1] ZHOU Yao Sheng. Research on Field Power Test System and Power Influencing Factors of Oilfield Diesel Engine [D]. Southwest Petroleum University. 2014

[2] LI Fei Peng. Construction and Principle of Internal Combustion Engine (Second Edition) [M]. China Railway Publishing House. 2003.

[3] LI Zong Shuai, DONG Chun, LIU Yan. Development and Application Actuality on Electric Power Dynamometer [J]. Electric Machines \& Control Application.2007. 34(5): 1-4.

[4] LIU Jian Xin , TAN Rong Wang. A Further Experimental Investigation on Diesel Engine's Power Measuring at Free Load $[\mathrm{J}]$. Vehicle Engine. 1992(1):56-59.

[5] ZHANG Jiang Han. Principle and Application of No load Measuring Work for Automobile Engine [J]. Automobile Technology. 1995(12):44-48.

[6] ZHAO Ying Xun. Determination of Engine Equivalent Moment of Inertia [J]. Journal of Automobile Transportation. 1989(10):36-37.

[7] LI Juan. Research on the Transient Speed Signal of Internal Combustion Engine [D]. ShanDong University, 2009.

[8] HU Yu Ping, ZHANG Li Mei. A Testing Method for Determining Inertia of Internal Combustion Engine [J]. Internal Combustion Engines. 2001(2):20-22.

\section{Volume 6 Issue 7, July 2017 www.ijsr.net}




\section{International Journal of Science and Research (IJSR) \\ ISSN (Online): 2319-7064}

Index Copernicus Value (2015): 78.96 | Impact Factor (2015): 6.391

[9] YU Ming Jin, CHENG Yong, WU Bo, et al. New Method for Estimating the Inertia Moment of an Engine [J]. Transactions of the Chinese Society of Agricultural Machinery, 2005, 36(6):34-37.

[10] LIU Yi, LIU Xun Jun, Bai Ling, et al. Additional Mass Method to Determine the Moment of Inertia of Total Moving Components in a Engine [J]. Transactions of CSICE. 1992(4):323-328.

[11]LIU Wei Guo, ZHANG Li Mei. Measurement of Instantaneous Speed of Internal Combustion Engine [J]. Transactions of CSICE. 1999. 17(4):388-390.

[12]LIU Hong Wen. Advanced Materials Mechanics [M].Higher Education Press, 1985.

[13] MA Ming Jian. Data Acquisition and Processing Technology (Second Edition) [M]. XiAn JiaoTong University Press. 2005.

[14] JIANG Qing ming, YANG Xu, GAN Yong mei. A New Way of Measuring Velocity and Acceleration Based on Photoeletric Encoder [J]. Microcomputer Information: Automation of Controller, 2004, 20(6): 48-49.

Volume 6 Issue 7, July 2017 www.ijsr.net 